\title{
Evaluation of Effects of Bivalent Cations on the Formation of Purine-rich Triple-Helix DNA by ESI-FT-MS
}

\author{
Cuihong Wan, Meng Cui, Fengrui Song, Zhiqiang Liu, and Shuying Liu \\ Changchun Center of Mass Spectrometry, Changchun Institute of Applied Chemistry, Chinese Academy of
} Sciences, Changchun, China

The GGA triplet repeats are widely dispersed throughout eukaryotic genomes. (GGA)n or (GGT)n oligonucleotides can interact with double-stranded DNA containing (GGA:CCT)n to form triple-stranded DNA. The effects of 8 divalent metal ions ( 3 alkaline-earth metals and 5 transition metals) on formation of these purine-rich triple-helix DNA were investigated by electrospray ionization Fourier transform ion cyclotron resonance mass spectrometry (ESI-FTMS). In the absence of metal ions, no triplex but single-strand, duplex, and purine homodimer ions were observed in mass spectra. The triple-helix DNA complexes were observed only in the presence of certain divalent ions. The effects of different divalent cations on the formation of purine-rich triplexes were compared. Transition-metal ions, especially $\mathrm{Co}^{2+}$ and $\mathrm{Ni}^{2+}$, significantly boost the formation of triple-helix DNA, whereas alkaline-earth metal ions have no positive effects on triplex formation. In addition, $\mathrm{Ba}^{2+}$ is notably beneficial to the formation of homodimer instead of triplex. (J Am Soc Mass Spectrom 2009, 20, 1281-1286) (C) 2009 American Society for Mass Spectrometry

$\mathrm{T}$ Triple helices have drawn great attention with respect to their role in transcriptional regulation and replication in eukaryotes [1]. Recognition of a purine strand of polypurine-polypyrimidine [poly(R: Y)] (R: purine, Y: pyrimidine) target duplex DNA by triplex-forming oligonucleotides (TFO) inhabiting the major groove was achieved by Hoogsteen or reverseHoogsteen hydrogen bonds. The triplex DNA can be categorized in pyrimidine motif $\left(Y^{*} R: Y\right)$ and purine motif ( $\left.R^{*} R: Y\right)$, depending on the base composition of the third strand and its binding orientation to the target duplex DNA. In the pyrimidine motif, the third strand consisting of cytosine and thymine binds parallel to the purine strand of duplex via Hoogsteen bonds and the N3 of cytosine is required to be protonated under acidic conditions. Because it is $\mathrm{pH}$ dependent, pyrimidine does not usually bind to DNA at physiologic $\mathrm{pH}$ without further modification [1-3]. In the purine motif, the third strand binds to the purine strand in duplex with binding of A to A:T, G to G:C, and T to A:T base pairs (Figure 1), requires no base protonation, and primarily exhibits $\mathrm{pH}$-independent binding. The third strand containing G/A bases binds antiparallel to the purine strand of the duplex, whereas the third strand containing $\mathrm{G} / \mathrm{T}$ bases binds either parallel or antiparallel to the purine strand of the duplex. For the purine motif, the triplex will be inhibited in the presence of

Address reprint requests to Prof. Shuying Liu, Changchun Institute of Applied Chemistry, Chinese Academy of Sciences, Changchun Center of Mass Spectrometry, 5625 Renmin Street, Changchun, Jilin 130022, China. E-mail: mslab@ciac.jl.cn monovalent cations, such as sodium and potassium, which serve to coordinate and stabilize the G-rich oligonucleotide dimmers and tetramers $[1,4]$. The stabilization of the bivalent cation to triplex is complicated-i.e., it is not a simple electrostatic phenomenon-and has been investigated using circular dichroism, UV absorption spectroscopy, footprinting techniques, electrophoresis mobility shift assay, and laser densitometry [5-11].

As a soft ionization technique, electrospray ionization mass spectrometry (ESI-MS) has wide application in the analysis of noncovalent complexes and shows several prominent advantages in determination of stoichiometry, sensitivity, and speed. ESI-MS has been used for studies of noncovalent oligonucleotide complexes, including detection of complex structures of oligonucleotides in the gas phase, such as DNA hairpins, duplexes, triplexes, and quadruplexes [12-17]. Besides extensive studies of interactions between various DNA and drugs and proteins, the interactions of metals with nucleobases and oligonucleotides have been investigated [17-21]. Since 2002, noncovalent triplex DNA complexes have been studied by mass spectrometry, although all of them focused on the pyrimidine motif [13-15]. To the best of our knowledge, this is the first investigation on the interactions between the purine motif and bivalent-cation metals using ESI-MS. ESI-MS can obtain binding stoichiometries for small amounts of analytes to DNA. Furthermore, specificity, binding affinity, and binding site of metal cation can be determined by ESI-MS and tandem mass spectrometry [18, 20, 21]. 

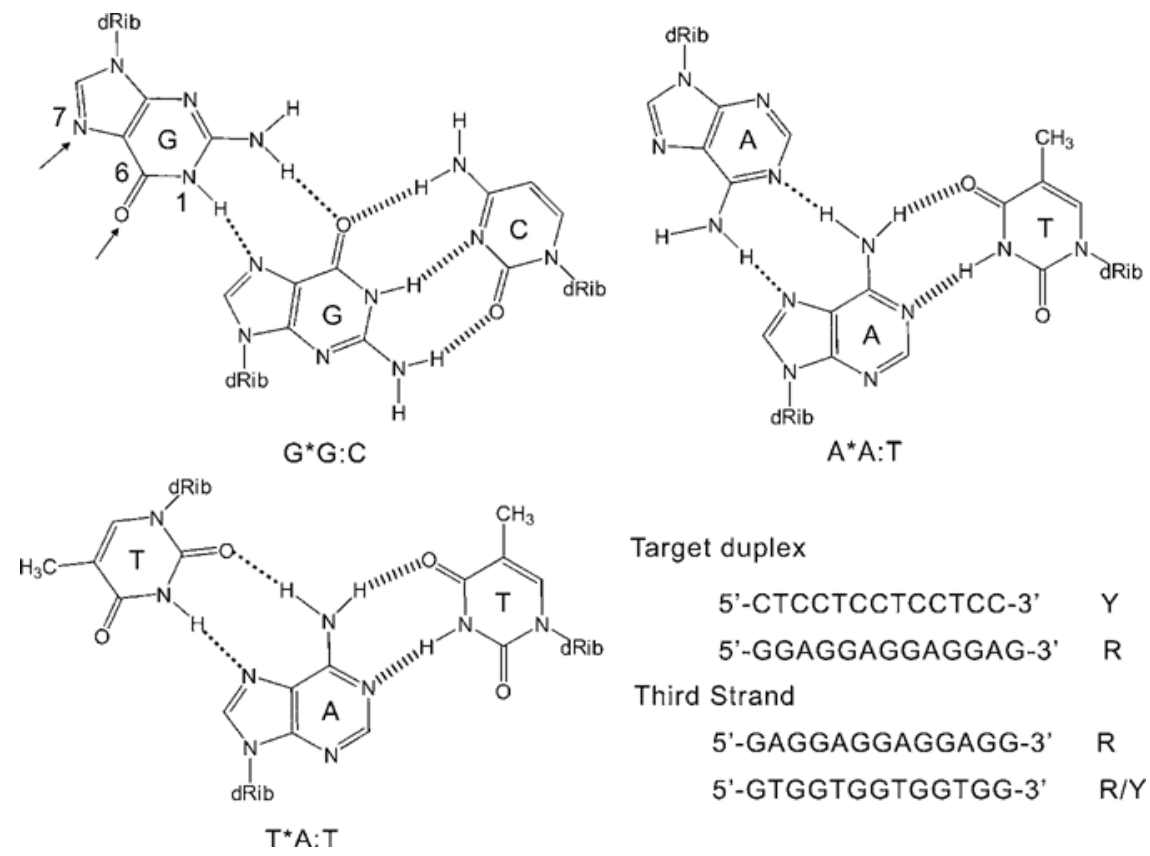

Target duplex

5'-СТССТССТССТСС-3' Y

5'-GGAGGAGGAGGAG-3' R

Third Strand

5'-GAGGAGGAGGAGG-3' R

5'-GTGGTGGTGGTGG-3' R/Y

Figure 1. Schematic diagrams of $G^{*} G: C, A^{*} A: T$ and $T^{*} A: T$ triplets with reverse-Hoogsteen $(\cdots)$ and Watson-Crick (W-C) $(\backslash \backslash \backslash)$ hydrogen bonds in triplex DNA, and the sequences of the DNA triplexes studied. (Y: strand containing only pyrimidine; R: strand containing only purine; R/Y: strand containing both purine and pyrimidine.)

The GGA triplet repeat, which is widely dispersed throughout eukaryotic genomes, has been found in microsatellite DNA of the rat polymeric immunoglobulin receptor gene and has also been identified in portions of human and mouse cellular DNA, which cross-hybridizes with the internal direct repeat IR3 repetitive region of Epstein-Barr virus [22, 23]. It has been found that (GGA)n oligonucleotides can form homoduplex or quadruplex under certain conditions, and triple-strand DNA complexes with double-strand DNA containing (GGA:CCT)n [24, 25]. In this work, the effects of various divalent metal ions on the formation of purine-rich triple-helix DNA between GGA or GGT oligonucleotides and target duplex (GGA:CCT) were studied by electrospray ionization Fourier transform ion cyclotron resonance mass spectrometry (ESI-FTICR-MS).

\section{Experimental}

\section{Materials}

Manganese acetate was purchased from Aldrich (Milwaukee, WI, USA), nickel(II) acetate from Fluka Chemie (Buchs, Switzerland), zinc acetate from Sigma Chemical Co. (St. Louis, MO, USA), and five other acetates were purchased from Beijing Chemical Reagent Factory (Beijing, China). All acetate reagents were dissolved in Milli-Q water (Millipore, Billerica, MA, USA) at a concentration of $100 \mathrm{mM}$. Single-strand oligodeoxynucleotides (5'-CTC CTC CTC CTCC-3' CCT, 5'GGA GGA GGA GGAG-3' GGA, 5'-GAG GAG GAG
GAGG-3' GGA2, 5'-GTG GTG GTG GTGG-3' GGT) were purchased from Takara Biotechnology Co., Ltd. (Dalian, China) and used without further purification. Stock solutions of each single strand were prepared at 1 $\mathrm{mM}$ concentration in Milli-Q water and the concentrations were estimated by their UV absorbance at 260-nm wavelength with the extinction coefficients provided by the following website: http://scitools.idtdna.com/ analyzer/Applications/OligoAnalyzer/. The solutions containing three single strands (CCT + GGA + GGA2 or CCT + GGA + GGT) in $150 \mathrm{mM}$ ammonium acetate $(\mathrm{pH}=6.8)$, with or without divalent metal ions, were heated to $90^{\circ} \mathrm{C}$ for $15 \mathrm{~min}$ and slowly cooled at $4{ }^{\circ} \mathrm{C}$ overnight to form the DNA triplexes (tsGGA or tsGGT). The solutions of DNA duplex (mixture of GGA and CCT) or single strands (CCT, GGA, or GGT) were annealed at $90^{\circ} \mathrm{C}$ at the same conditions as the DNA triplex.

\section{Mass Spectrometry}

The stock solutions of DNA were diluted with $\mathrm{H}_{2} \mathrm{O}$ / $\mathrm{MeOH}$, giving a final concentration of DNA of $10 \mu \mathrm{M}$ and $20 \% \mathrm{MeOH}$, and directly injected into the source region at a rate of $4 \mu \mathrm{L} / \mathrm{min}$. All ESI mass spectra in negative-ion mode were acquired using an IonSpec HiRes Fourier transform ion cyclotron resonance mass spectrometer (FT-ICR-MS) (Lake Forest, CA, USA) with a 7-T shielded superconducting magnet and a Micromass Z-spray electrospray source. The spray voltage, 
source, and probe temperature were set at $2400 \mathrm{~V}, 80$ and $100{ }^{\circ} \mathrm{C}$, respectively.

\section{Results and Discussion}

\section{DNA Motif without Metal Ions}

Solutions containing DNA single strands were annealed and detected by ESI-MS respectively. For single-strand CCT, peaks corresponding to the single strand in 3- and 4- charged ions and dimer in 5- charged ions were observed in the mass spectra (Figure 2a). Besides these, $\mathrm{NH}_{4}{ }^{+}$adduct ions of purine homodimers (GGA:GGA $\left[\mathrm{D}_{\mathrm{R}: \mathrm{R}}+3 \mathrm{NH}_{4}{ }^{+}\right]^{5-}$ at $m / z$ 1670.467; GGT:GGT $\left[\mathrm{D}_{\mathrm{R} / \mathrm{Y}: \mathrm{R} / \mathrm{Y}}+\right.$ $\left.3 \mathrm{NH}_{4}{ }^{+}\right]^{5-}$ at $m / z$ 1656.090) were also detected for both GGA and GGT (Figure $2 b$ and $c$ ). Figure $2 d$ shows the mass spectra of target DNA duplex, the mixture of single strands CCT and GGA in 1:1 $\mathrm{M}$ ratio. The peaks corresponding to normal Watson-Crick (W-C) duplex (GGA:CCT $\left[\mathrm{D}_{\mathrm{R}: \mathrm{Y}}\right]^{6-}$ at $m / z$ 1317.369) and unbound single strands are observed as well. Mixtures of target duplex and the third strand GGA2 or GGT were also analyzed by ESI-MS. Only the peaks of single strands, W-C duplex, and homodimer were observed, and no peak of trimer complex was detected at all in the mass spectra (Figure 2e and f). Because the GGA and GGT form a homodimer, ssCCT became the base peak in the spectra.

The $\mathrm{NH}_{4}{ }^{+}$adducts of homodimers were mainly observed, whereas that of the W-C duplex was not detected, which suggested that the homodimers may have structures different from those of $\mathrm{W}-\mathrm{C}$ duplexes. There are two possible structures, homoduplex and quadruplex, for this homodimer, since (GGA)n and (GGT)n were found to form either homoduplex or quadruplex in the solution [24, 25]. The G-quadruplex shows a tendency to embed $\mathrm{NH}_{4}{ }^{+}$between two Gquartets, to stabilize its structure, and yields $\mathrm{NH}_{4}{ }^{+}$ adducts of G-quartets in the ESI-MS spectra [15, 16]. The specific interactions between cations and homoduplexes have not yet been systematically investigated. If the homodimer is homoduplex, this indicates that the homoduplex might be stabilized by cations and can form specific cation additions just like G-quadruplex does.

\section{Mixtures of Metal Ions and DNA}

Among numerous metal ions, the interaction of alkaline-earth metal $\mathrm{Mg}^{2+}$ and triplex DNA has been
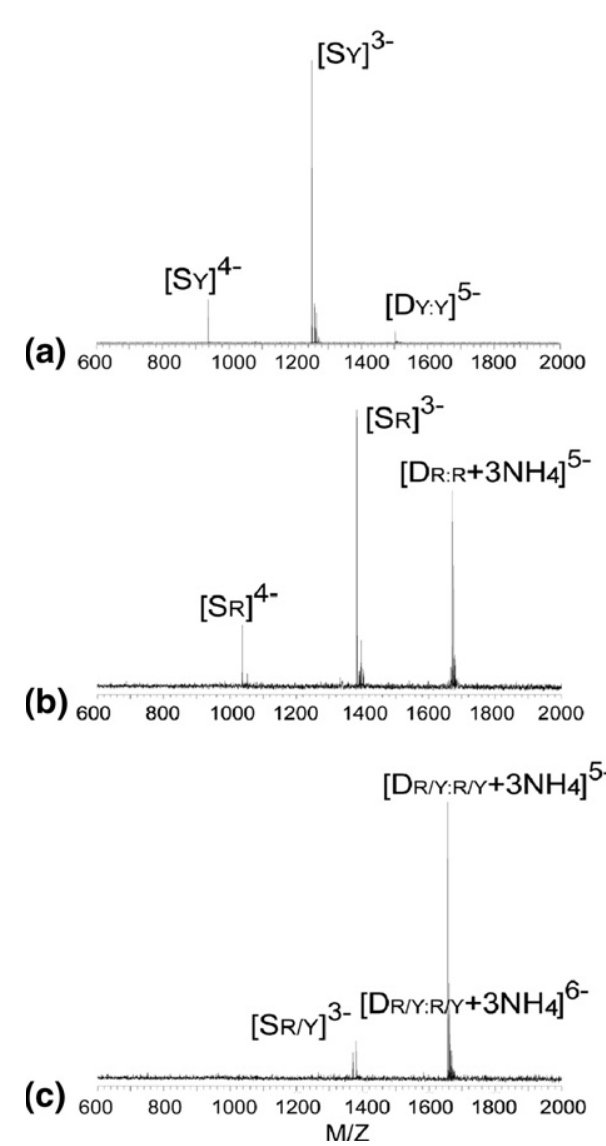
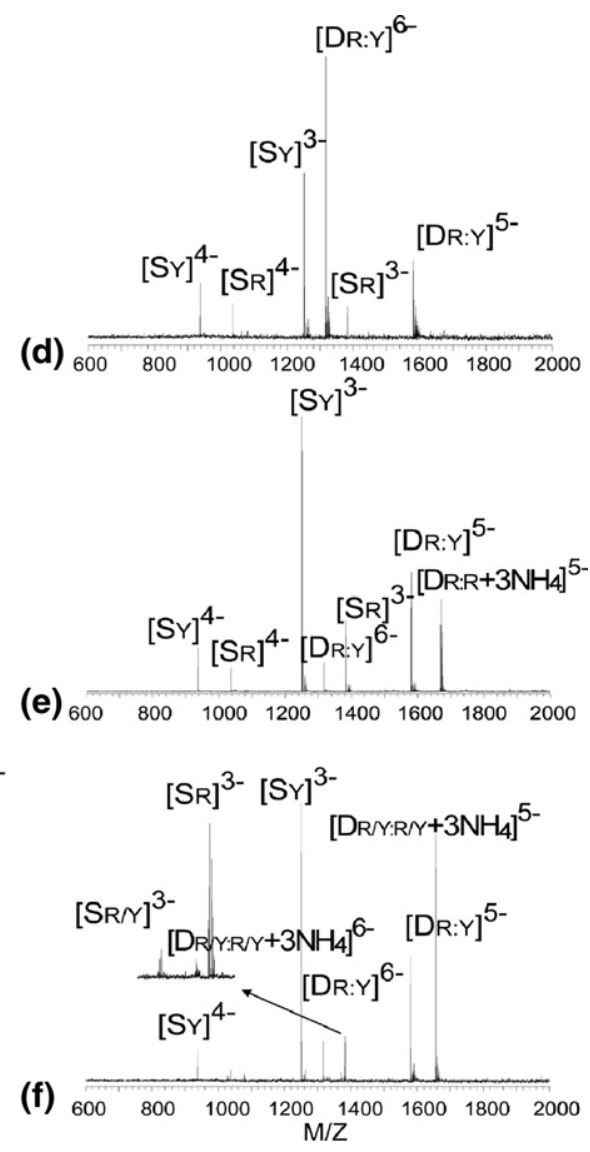

Figure 2. ESI-MS spectra of single strands CCT (a), GGA (b), GGT (c) and target duplex (d), and mixture of target duplex with GGA (e) or GGT (f) in $150 \mathrm{mM}$ ammonium acetate $(\mathrm{pH}=6.8)$. $\left(\mathrm{D}_{\mathrm{R}: Y}\right.$ : W-C duplex GGA:CCT; $D_{R: R}$ : purine homodimer GGA:GGA; $D_{R / Y: R / Y}$ : purine homodimer GGT: GGT). 
widely investigated, although it does not stabilize the intermolecular $\mathrm{d}(\mathrm{TC}) \mathrm{n} \cdot \mathrm{d}(\mathrm{GA}) \mathrm{n} \cdot \mathrm{d}(\mathrm{AG}) \mathrm{n}$ triplex, but stabilizes the $d(C) n \cdot d(G) n \cdot d(G) n$ triplex $[10,11]$. In this work, alkaline-earth metal ions $\mathrm{Mg}^{2+}, \mathrm{Ca}^{2+}$, or $\mathrm{Ba}^{2+}$ were added to the mixture of three single-strand oligodeoxynucleotides before annealing. The annealed mixtures were analyzed by ESI-MS and the results are shown in Figure 3. The addition of 10 equivalents of $\mathrm{Mg}^{2+}$ to the mixtures of three oligonucleotides resulted in the formation of noncovalent complexes containing one magnesium ion bound to single strand or duplex. For tsGGA (mixture of CCT + GGA + GGA2), no peaks of homodimer were observed and tiny peaks assigned to the triplex complex were observed in the spectra as well, whereas for tsGGT (mixture of CCT + GGA + GGT) no peak corresponding to a triplex was observed (Figure $3 \mathrm{a}$ and $\mathrm{b}$ ). When $\mathrm{Ba}^{2+}$ was added to the mixtures, the complexes of $\mathrm{Ba}^{2+}$ with single strand and homodimer were observed in the spectra in the forms of $\left[\mathrm{S}+\mathrm{Ba}^{2+}\right]^{3-}$ and $\left[\mathrm{D}+2 \mathrm{Ba}^{2+}\right]^{5-}$ (Figure $3 \mathrm{c}:\left[\mathrm{D}_{\mathrm{R}: \mathrm{R}}+\right.$ $\left.2 \mathrm{Ba}^{2+}\right]^{5-}$ at $m / z$ 1714.621; Figure 3d: $\left[\mathrm{D}_{\mathrm{R} / \mathrm{Y}: \mathrm{R} / \mathrm{Y}}+\right.$ $\left.2 \mathrm{Ba}^{2+}\right]^{5-}$ at $m / z 1700.199$ and $\left[\mathrm{D}_{\mathrm{R}: \mathrm{R}}+2 \mathrm{Ba}^{2+}\right]^{5-}$ at $m / z$
1714.623). However, the peaks of $\mathrm{W}-\mathrm{C}$ duplexes were observed without $\mathrm{Ba}^{2+}$ addition. The $\mathrm{R}$ and $\mathrm{R} / \mathrm{Y}$ single strands show higher affinities for $\mathrm{Ba}^{2+}$ than $\mathrm{Y}$ strand. Analogous ions were observed in the spectra of DNA mixtures with and without $\mathrm{Ca}^{2+}$, suggesting that $\mathrm{Ca}^{2+}$ has no effect on the triplex DNA formation.

It should be noted that $\mathrm{Mg}^{2+}$ ions can form complexes with single strands, W-C duplexes, and homodimers, whereas $\mathrm{Ba}^{2+}$ ions can form complexes with single strands and homodimers. Additionally, the $\mathrm{NH}_{4}{ }^{+}$ions were maintained when $\mathrm{Mg}^{2+}$ ions attached to DNA strands; however, the $\mathrm{NH}_{4}{ }^{+}$ions were replaced when $\mathrm{Ba}^{2+}$ ions attached to homodimers. These results imply that the interaction sites or modes of $\mathrm{Mg}^{2+}$ differ from those of $\mathrm{Ba}^{2+}$, whereas $\mathrm{Ba}^{2+}$ ions occupy the same binding sites as $\mathrm{NH}_{4}{ }^{+}$with higher binding affinities than $\mathrm{NH}_{4}{ }^{+}$, which will be discussed in the next section.

Taking $\mathrm{Co}^{2+}$ as an example, mass spectra of DNA mixtures in the presence of $100 \mu \mathrm{M} \mathrm{Co}^{2+}$ ions are shown in Figure 3. With the addition of $\mathrm{Co}^{2+}$, triplex complexes were observed in the spectra. For tsGGA, the ions consisting of four $\mathrm{Co}^{2+}$ ions bound to the triple

(a)

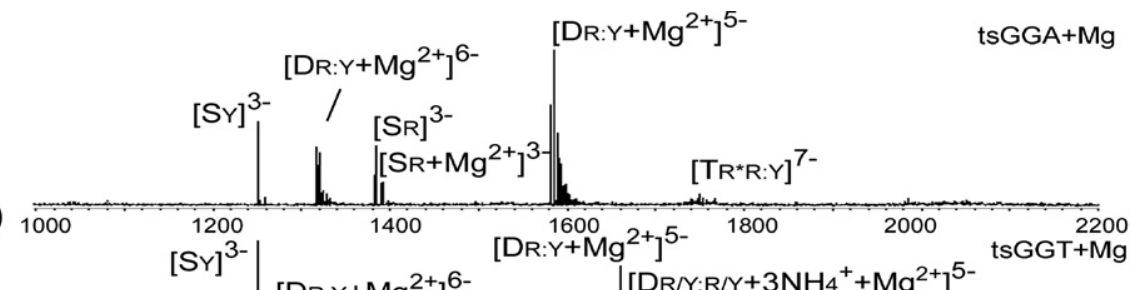

(b)

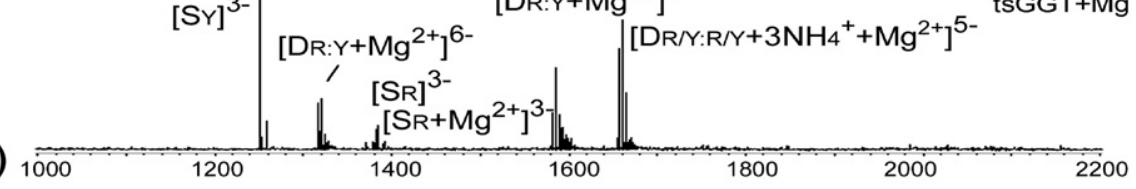

(c)

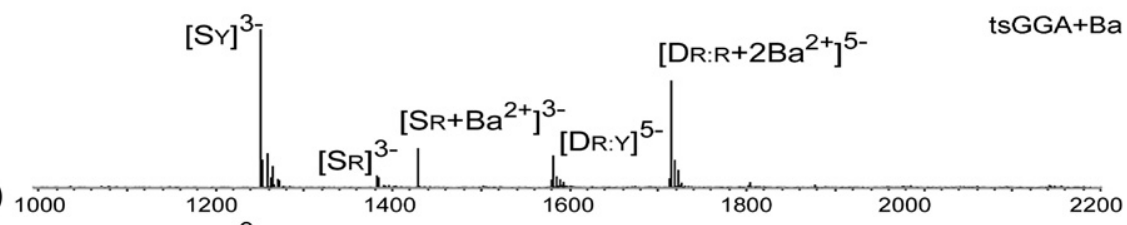

(d)

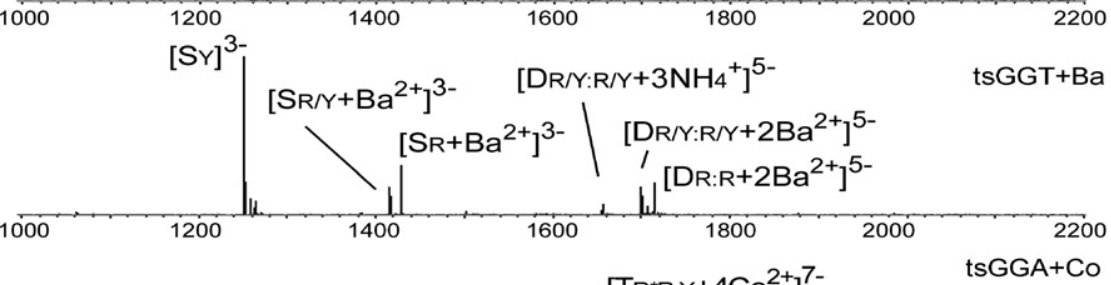

(e)

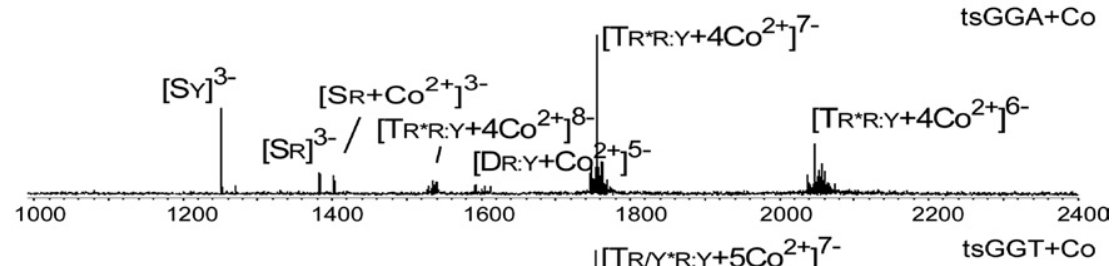

(f)

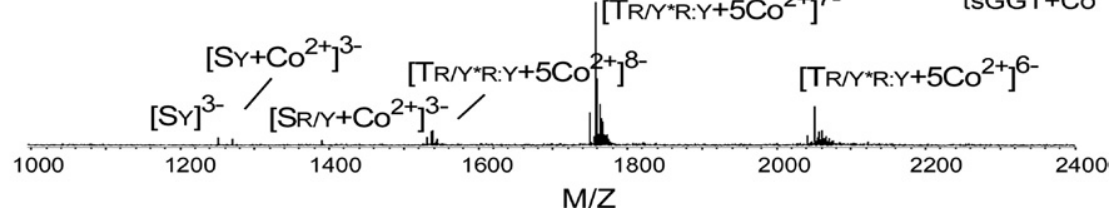

Figure 3. ESI-MS spectra of divalent metal ions $\mathrm{Mg}^{2+}(\mathbf{a}, \mathbf{b}), \mathrm{Ba}^{2+}(\mathbf{c}, \mathbf{d})$, or $\mathrm{Co}^{2+}(\mathbf{e}, \mathbf{f})$ mix with the triplex helix DNA tsGGA $(\mathbf{a}, \mathbf{c}, \mathbf{e})$ or tsGGT $(\mathbf{b}, \mathbf{d}, \mathbf{f})$. 
helix $\left(\left[\mathrm{T}_{\mathrm{R}^{*} \mathrm{R}: Y}+4 \mathrm{Co}^{2+}\right]^{7-}\right.$ at $\left.\mathrm{m} / \mathrm{z} 1757.965\right)$, as well as ions assigned to single-strand- $\mathrm{Co}^{2+}$ and duplex- $\mathrm{Co}^{2+}$ complexes (Figure 3e). For tsGGT the spectra was dominated by the triplex-5C $\mathrm{Co}^{2+}\left(\left[\mathrm{T}_{\mathrm{R} / \mathrm{Y}^{*} \mathrm{R}: \mathrm{Y}}+5 \mathrm{Co}^{2+}\right]^{7-}\right.$ at $\mathrm{m} / \mathrm{z}$ 1754.929) complex ions and only tiny single strands and their $\mathrm{Co}^{2+}$ addition ions could be observed (Figure 3f). Analogous ions were also observed in mass spectra of DNA mixtures with the addition of $\mathrm{Ni}^{2+}$ and $\mathrm{Zn}^{2+}$. The mass spectra of mixtures of $\mathrm{Cu}^{2+}$ and $\mathrm{Mn}^{2+}$ with DNA are also similar, where the peak abundances of triplexes are quite low, with nearly $10 \%$ relative abundance. When the ratio of metal ion and DNA decreased to 4:1 ( $40 \mu \mathrm{M}$ for metal ions), ESI-MS spectra were similar to that of pure DNA. The peaks corresponding to metal-DNA complexes decrease sharply, especially for tsGGA, and triplex ions can be observed only in mixtures with $\mathrm{Co}^{2+}$ or $\mathrm{Ni}^{2+}$ (Supplemental Figure S1), which can be found in the electronic version of this article).

The DNA duplex annealed with $\mathrm{Co}^{2+}$ yields singlestrand, duplex, and corresponding metal adduct ions; no triplex ion (Supplemental Figure S2) was observed. As trapping times are increased, the intensities of metal adduct ions increased gradually, indicating that gasphase nonspecific complexes of the metal ions with analytes were formed during the electrospray process. To prove the triplex complexes mainly formed in the solution, 10-fold of metal ions in equivalence were added to the annealed DNA mixtures before ESI analysis. Taking tsGGT mixtures with $\mathrm{Ba}^{2+}$ and $\mathrm{Co}^{2+}$ as examples (Supplemental Figure S3), the metal ion adducts of single strand and W-C duplex, as well as $\mathrm{NH}_{4}{ }^{+}$ adducts of homodimer, were observed in the ESI-MS spectrum; no triplex DNA complex was observed. Additionally, the third strand was replaced with an uncomplementary strand. After the mixture of the target duplex DNA and the uncomplementary single strand was annealed in the presence of $\mathrm{Co}^{2+}$, no triplex ion was observed in the ESI mass spectrum (Supplemental Figure S4). These results suggest that the observed DNA triplex complexes were specifically formed in solution with the assistance of certain metal ions.

\section{Effects of Divalent Metal Ions on Formation of Purine-rich Triple-Helix DNA}

To compare the effects of divalent metal ions to formation of purine-rich triple-helix DNA, the fractions of triple helix were calculated with the following equation:

Fraction of triple helix $=\mathrm{I}_{\text {triplex }} /\left(\mathrm{I}_{\text {duplex }}+\mathrm{I}_{\text {triplex }}\right)$

where I represents the relative intensities of free DNA or DNA-metal complexes.

Figure 4 shows the fractions of triplex DNA in the mixtures of divalent metal ions and DNA strands. The higher values of the fractions of triplex DNA indicate more triplex formed and greater stabilization of metal ions to triplex DNA. It is indicated that the stabilization

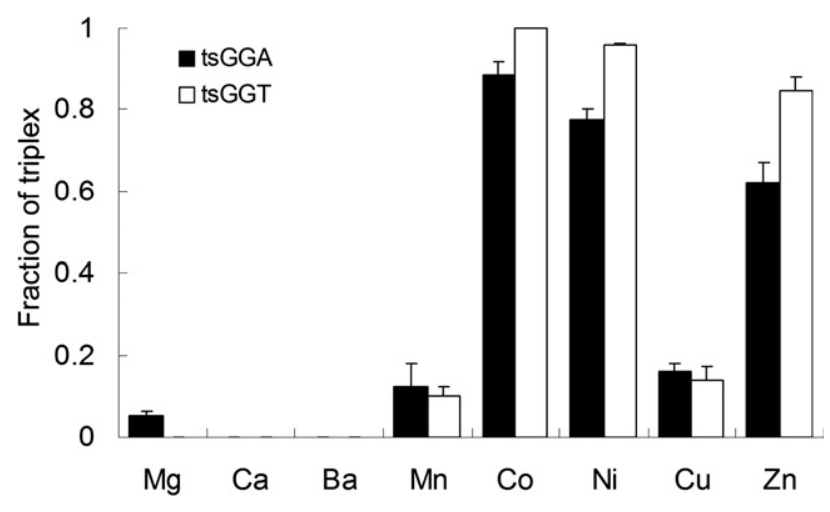

Figure 4. Fractions of triplex based on five times ESI-MS measurements of divalent ions and triplexes mixtures.

of divalent cations to purine-rich triplexes is in the order of $\mathrm{Co}^{2+} \approx \mathrm{Ni}^{2+}>\mathrm{Zn}^{2+}>\mathrm{Cu}^{2+} \approx \mathrm{Mn}^{2+}>\mathrm{Mg}^{2+}$. $\mathrm{Ca}^{2+}$ and $\mathrm{Ba}^{2+}$ do not stabilize the purine motif triplexes and $\mathrm{Ba}^{2+}$ significantly stabilizes the homodimer.

The effects of bivalent cations on triplex formation are not yet well understood. Based on the aforementioned results, the effects of metal ions on formation of purine-rich triple-helix DNA are considered to be the charge neutralization - to reduce the repulsion between three phosphate frameworks-because triplex DNA has a higher charge density than that of either duplex or single-strand DNA. Besides binding phosphate, divalent cations have been found to interact with various sites on nucleic acid, including $\mathrm{N}$ and $\mathrm{O}$ of bases [26, 27]. When an electrophile interacts with N7, the formation of reverse-Hoogsteen hydrogen bonds would be enhanced, thus improving the stability of the purinerich triplex $[6,10,28]$. Although $\mathrm{Mg}^{2+}$ may coordinate with N7 and O6 of guanine (Figure 1), it is primarily bound to the phosphate group [27] and slightly assists the formation of triplexes. Because transition-metal ions, especially $\mathrm{Co}^{2+}, \mathrm{Ni}^{2+}$, and $\mathrm{Zn}^{2+}$, show higher affinities for purine N7 than alkaline-earth metal ions $[10,28]$, they can efficiently enhance the reverseHoogsteen hydrogen bonds and boost formation of the triplex.

Inhibiting self-structures of G-rich oligonucleotides may be the other reason. Since self-association of G-rich oligonucleotides could decrease triplex formation, inhibitory effects of monovalent cations (especially $\mathrm{K}^{+}$) on purine-rich triplex formation might relate to the promotion of such competing self-structures $[6,9]$. In this work, $\mathrm{Ba}^{2+}$ ions have been found to enhance the formation of homodimers, so it might inhibit triplex formation like $\mathrm{K}^{+}$does. It has been proved that cations with an ionic radius in the range $1.3-1.5 \AA$ fit well within two G-quartets and facilitate self-aggregate of G-rich oligonucleotides, and $\mathrm{Ba}^{2+}$ with the ionic radius $1.34 \AA$ assists this self-aggregate more efficiently than $\mathrm{NH}_{4}{ }^{+}$(ionic radius $1.43 \AA$ ) [29]. $\mathrm{Mg}^{2+}$ with an ionic radius of $0.65 \AA$ is too small to inlay into the G-quartets, which might be the reason that $\mathrm{NH}_{4}{ }^{+}$coordinated with homodimer could be replaced by $\mathrm{Ba}^{2+}$ but not by $\mathrm{Mg}^{2+}$. 
The differential between $\mathrm{Ba}^{2+}$ and $\mathrm{Mg}^{2+}$ implies that the cation size is an important factor for the binding mechanism. The sizes of transition-metal ionic radii $\left(\mathrm{Co}^{2+}, 0.78 \AA ; \mathrm{Ni}^{2+}, 0.78 \AA ; \mathrm{Zn}^{2+}, 0.74 \AA ; \mathrm{Mn}^{2+}, 0.80 \AA\right.$; $\mathrm{Cu}^{2+}, 0.69 \AA$ [30]) may be involved in their coordination to triplex. Taking ion radius into account, we might draw the assumption that an ionic radius in the range $0.74-0.78 \AA$ is the optimal size for a cation to boost and stabilize the structures of GGA*GGA:CCT and GGT* GGA:CCT triplexes.

\section{Conclusion}

The nonconvalent complexes of 8 divalent metal ions with triple-helix DNA were studied using negative ion ESI-MS. The presence of divalent metal ions plays an indispensable role to formation of purine-rich triplehelix DNA. Compared with alkaline-earth metal ions, transition-metal ions, especially $\mathrm{Co}^{2+}$ and $\mathrm{Ni}^{2+}$, show superiority in the boosting of triplex DNA formation. On the contrary, $\mathrm{Ba}^{2+}$ ion facilitates the formation of homodimer. The effects of metal ions on formation of purine-rich triple-helix DNA are very complicated, which are related not only to simple electrostatic phenomena but also to the ion radii, binding sites, and some uncertain factors. Although the secondary and tertiary structures of DNA complexes, such as purine homodimer, are not well known at present, ESI-MS displays its unique advantages in speed, stoichiometries, and sensitivity in analysis of noncovalent interactions between metal ions and nucleic acids.

\section{Acknowledgments}

This work was supported by the National Natural Science Foundation of China (Grants 20873137 and 30672600) and Science and Technology Development Project of Jilin Province (Grant 20070552).

\section{Appendix A Supplementary Material}

Supplementary material associated with this article may be found in the online version at doi:10.1016/ j.jasms.2009.02.026.

\section{References}

1. Chan, P. P.; Glazer, P. M. Triplex DNA: Fundamentals, Advances, and Potential Applications for Gene Therapy. J. Mol. Med. 1997, 75, 267-282.

2. Sugimoto, N.; Wu, P.; Hara, H.; Kawamoto, Y. pH and Cation Effects on the Properties of Parallel Pyrimidine Motif DNA Triplexes. Biochemistry 2001, 40, 9396-9405.

3. Fox, K. R. Targeting DNA with Triplexes. Curr. Med. Chem. 2000, 7, 17-37.

4. Cheng, A.-J.; Van Dyke, M. W. Monovalent Cation Effects on Intermolecular Purine-Purine-Pyrimidine Triple-Helix Formation. Nucleic Acids Res. 1993, 21, 5630-5635.

5. Khomyakova, E. B.; Gousset, H.; Liquier, J.; Huynh-Dinh, T.; Gouyette, C.; Takahashi, M.; Florentiev, V. L.; Taillandier, E. Parallel Intramolecular DNA Triple Helix with $G$ and $T$ Bases in the Third Strand Stabilized by $\mathrm{Zn}^{2+}$ Ions. Nucleic Acids Res. 2000, 28, 3511-3516.
6. Floris, R.; Scaggiante, B.; Manzini, G.; Quadrifoglio, F.; Xodo, L. E. Effect of Cations on Purine Purine Pyrimidine Triple Helix Formation in Mixed-Valence Salt Solutions. Eur. J. Biochem. 1999, 260, 801-809.

7. Blume, S. W.; Lebowitz, J.; Zacharias, W.; Guarcello, V.; Mayfield, C. A.; Ebbinghaus, S. W.; Bates, P.; Jones, D. E., Jr.; Trent, J.; Vigneswaran, N.; Miller, D. M. The Integral Divalent Cation within the Intermolecular Purine - Purine - Pyrimidine Structure: A Variable Determinant of the Potential for and Characteristics of the Triple Helical Association. Nucleic Acids Res. 1999, 27, 695-702.

8. Sponer, J.; Sabat, M.; Burda, J. V.; Doody, A. M.; Leszczynski, J.; Hobza P. Stabilization of Purine-Purine-Pyrimidine DNA Triplets by Divalent Metal Cations. J. Biomol. Struct. Dyn. 1998, 16, 139-143.

9. Noonberg, S. B.; Francois, J.-C.; Garestier, T.; Helene, C. Effect of Competing Self-Structure on Triplex Formation with Purine-Rich Oligodeoxynucleotides Containing GA Repeats. Nucleic Acids Res. 1995, 23, 1956-1963.

10. Potaman, V. N. Soyfer, V. N. Divalent Metal Cations upon Coordination to the N7 of Purines Differentially Stabilize the PyPuPu DNA Triplex Due to Unequal Hoogsteen-Type Hydrogen Bond Enhancement. J. Biomol. Struct. Dyn. 1994, 11, 1035-1040.

11. Malkov, V. A.; Voloshin, O. N.; Soyfer, V. N.; Frank-Kamenetskii, M. D. Cation and Sequence Effect on Stability of Intermolecular PyrimidinePurine-Purine Triplex. Nucleic Acids Res. 1993, 21, 585-591.

12. Guo, X.; Liu, Z.; Liu, S.; Bentzley C. M.; Bruist, M. F. Structural Features of the L-Argininamide-Binding DNA Aaptamer Studied with ESIFTMS. Anal. Chem. 2006, 78, 7259-7266.

13. Wan, C.: Guo, X.: Liu, Z: Liu. S. Studies of the Intermolecular DNA Triplexes of $\mathrm{C}^{+} \cdot \mathrm{GC}$ and $\mathrm{T} \cdot \mathrm{AT}$ Triplets by Electrospray Ionization Fourier-Transform Ion Cyclotron Resonance Mass Spectrometry. J. Mass Spectrom. 2008, 43, 164-172.

14. Santhana Mariappan, S. V.; Cheng, X.; van Breemen, R. B.; Silks, L. A. Gupta, G. Analysis of GAA/TTC DNA Triplexes Using Nuclear Magnetic Resonance and Electrospray Ionization Mass Spectrometry. Anal. Biochem. 2004, 334, 216-226.

15. Rosu, F.; Gabelica, V.; Houssier, C.; De Pauw, E. Triplex and Quadruplex DNA Structures Studied by Electrospray Mass Spectrometry. Rapid Commun. Mass Spectrom. 2002, 16, 1729-1736.

16. Guo, X.; Liu, S.; Yu, Z. Bimolecular Quadruplexes and Their Transitions to Higher-Order Molecular Structures Detected by ESI-FTICR-MS J. Am. Soc. Mass Spectrom. 2007, 18, 1467-1476.

17. Vairamani, M.; Gross, M. L. G-Quadruplex Formation of ThrombinBinding Aptamer Detected by Electrospray Ionization Mass Spectrometry. J. Am. Chem. Soc. 2003, 125, 42-43.

18. Beck, J. L.; Colgrave, M. L.; Ralph, S. F.; Sheil, M. M. Electrospray Ionization Mass Spectrometry of Oligonucleotide Complexes with Drugs, Metals, and Proteins. Mass Spectrom. Rev. 2001, 20, 61-87.

19. Koch, K. J.; Aggerholm, T.; Nanita, S. C.; Cooks, R. G. Clustering of Nucleobases with Alkali Metals Studied by Electrospray Ionization Tandem Mass Spectrometry: Implications for Mechanisms of Multistrand DNA Stabilization. J. Mass Spectrom. 2002, 37, 676-686.

20. Favre, A.; Gonnet, F.; Tabet, J.-C. Location of the $\mathrm{Na}^{+}$Cation in Negative Ions of DNA Evidenced by Using MS $^{2}$ Experiments in Ion Trap Mass Spectrometry. Int. J. Mass Spectrom. 1999, 190/191, 303-312.

21. Wu, Q.; Cheng, X.; Hofstadler, S. A.; Smith, R. D. Specific MetalOligonucleotide Binding Studied by High Resolution Tandem Mass Spectrometry. J. Mass Spectrom. 1996, 31, 669-675.

22. Koch, K. S.; Gleiberman, A. S. Aoki, T; Leffert, H. L; Feren, A Jones, A. L.; Fodor, E. J. Discordant Expression and Variable Numbers of Neighboring GGA- and GAA-rich Triplet Repeats in the 30-Untranslated Regions of Two Groups of Messenger RNAs Encoded by the Rat Polymorphic Immunoglobulin Receptor Gene. Nucleic Acids Res. 1995, 23, 1098-1112.

23. Heller, M.; Flemington, E.; Kieff, E.; Deininger, P. Repeat Arrays in Cellular DNA Related to the Epstein-Barr Virus IR3 Repeat. Mol. Cell. Biol. 1985, 5, 457-465.

24. Matsugami, A.; Okuizumi, T.; Uesugi, S.; Katahira, M.; Intramolecular Higher Order Packing of Parallel Quadruplexes Comprising a G:G:G:G Tetrad and a G(:A):G(:A):G(:A):G Heptad of GGA Triplet Repeat DNA. J. Biol. Chem. 2003, 278, 28147-28153.

25. Sudal, T.; Mishima, Y.; Asakura1, H.; Kominami, R. Formation of a Parallel-Stranded DNA Homoduplex by d(GGA) Repeat Oligonucleotides. Nucleic Acids Res. 1995, 23, 3771-3777.

26. Gao, Y.-G.; Sriram, M.; Wang, A. H.-J. Crystallographic Studies of Metal Ion-DNA Interactions: Different Binding Modes of Cobalt(II), Copper(II) and Barium(II) to $\mathrm{N}^{7}$ of Guanines in Z-DNA and a Drug-DNA Complex. Nucleic Acids Res. 1993, 21, 4093-4101.

27. Bhattacharyya, R. G.; Nayak, K. K. Interaction of $\mathrm{Mg} \cdot \mathrm{ATP}^{2-}$ with DNA: Assessment of Metal Binding Sites and DNA Conformations by Spectroscopic and Thermal Denaturation Studies. Inorg. Chim. Acta 1988, 153, 79-86.

28. Sponer, J.: Sabat, M.; Gorb, L.; Leszczynski, J·; Lippert, B.; Hobza, P. The Effect of Metal Binding to the N7 Site of Purine Nucleotides on Their Structure, Energy, and Involvement in Base Pairing. J. Phys. Chem. B 2000, 104, 7535-7544.

29. Kankia, B. I.; Marky, L. A. Folding of the Thrombin Aptamer into a G-quadruplex with $\mathrm{Sr}^{2+}$ : Stability, Heat, and Hydration. J. Am. Chem. Soc. 2001, 123, 10799-10804.

30. Stark, J. G.; Wallace, H. G. Chemisry Data Book (translated by Yang, H. C.). Oil Industry Press: Bejing, 1980; p 33. 